\title{
SUBJECTIVE WELL-BEING IN TIMES OF COVID-19: POSITIVITY BIAS
}

\author{
Emma Otta, Renata Defelipe, Vinicius David, Vera Bussab \\ Departamento de Psicologia Experimental, Instituto de Psicologia, Universidade de São Paulo, \\ Brazil
}

emmaotta@usp.br

\begin{abstract}
The present study was aimed at investigating subjective well-being before and during COVID-19 pandemic among Brazilian adults. Brazil was one of the worst affected countries of the world in number of COVID-19 cases and deaths. Adults from the five macro-regions of the country answered an online survey in $2018(N=616)$, in $2020(N=379)$ and in $2021(N=845)$. An additional sample of 75 respondents participated at all three times in the survey. Respondents evaluated their current life satisfaction by a single-item measure with a 11-point scale and 5-item Satisfaction with Life Scale (SWLS) using a 7-point scale. They also evaluated how they felt about their lives now in comparison with a year ago and compared their quality of life against the lives of their parents. No differences were found as a function of the timing of the survey in all but one of the measures taken. There was a clustering of life satisfaction scores at around three-quarters of the measurement scale maximum as has been reported for Western and non-Western countries before the pandemic. Respondents' positive outlook on life was also evidenced by their personal retrospectives, by the self-comparison to one year ago but most clearly by comparison to parents' lives. Our findings showed that they compared themselves to their parents in a way to feel better about themselves. This positivity trend may be an adaptive characteristic of human nature that helps people recover from the slings and arrows of lived experiences.
\end{abstract}

Keywords: subjective well-being, COVID-19, positivity bias 


\section{INTRODUCTION}

Happiness is a central human theme. From an evolutionary perspective, subjective wellbeing signals advancement toward adaptive goals. (e.g., Grinde, 2012; Kenrick \& Krems, 2018). There is a worldwide increasing interest in subjective well-being (SWB) both among researchers and policymakers (Bartels, 2015; Diener \& Lucas, 1999). According to the Stiglitz Commission $(2009$, p. 12, p. 16), "research has shown that it is possible to collect meaningful and reliable data on subjective as well as objective well-being. (...) Quantitative measures of these subjective aspects hold the promise of delivering not just a good measure of quality of life per se, but also a better understanding of its determinants, reaching beyond people's income and material conditions. Despite the persistence of many unresolved issues, these subjective measures provide important information about quality of life."

The Organization for Economic Co-operation and Development (OECD) offers guidelines on measuring subjective well-being. These guidelines are international recommendations on collecting, analyzing and reporting data on SWB defined as "good mental states, including all of the various evaluations, positive and negative, that people make of their lives, and the affective reactions of people to their experiences" (OECD, 2013, p. 10). SWB is composed of a cognitive dimension, represented by global life satisfaction, and an affective dimension, represented by high positive affect and low negative affect (Diener, Suh, Lucas \& Smith, 1999; Deci \& Ryan, 2008). Life satisfaction (LS) is the cognitive dimension of SWB and refers to a general evaluation of the quality of life (QoL) that is over and above judgments of specific domains (e.g., family, friends) (Huebner, 1991). Happiness (HAPS) refers to the affective dimension and can be defined as the degree to which a person positively evaluates the overall quality of his/her own life as a whole (Veenhoven, 2014).

The coronavirus crisis, a pandemic of enormous proportions, has brought this thematic to the forefront. We are facing a worldwide social experiment that exposes human nature (Seitz et al., 2020; Karwowski et al., 2020). The World Happiness Report traced the distribution of happiness over 95 countries around the globe (Helliwell, Huang, Wang, \& Norton, 2021). Respondents were asked to report how satisfied they currently were with their life using the Cantril Ladder on a scale of $0-10$, from 0 at the bottom representing the worst possible life to 10 at the top representing the best possible life. The report showed that COVID-19 has led to relatively modest changes in the overall rankings, reflecting a generally shared resilience in the face of the pandemic. But it is notable that Brazil fell from position 29 in 2017-2019 (Mean score $=6.37695 \%$ CI 6.296-6.456) to position 41 in 2020 (Mean score $=6.11095 \%$ CI 5.888-6.332). Finland ranked first both in 2017-2019 (Mean score $=7.80995 \%$ CI 7.748-7.870 $)$ and in 2020 (Mean score $=7.889$ 95\% CI 7.784-7.999) and Zimbabwe ranked last (95) both in 2017-2019 (Mean score $=3.299$ 95\% CI 3.184-3.414) and in 2020 (Mean score $=3.16095 \%$ CI 2.954-3.365).

The present study was aimed at investigating subjective well-being by three core measures: (a) current overall life satisfaction; (b) overall affective evaluation in comparison to one year backward and (c) overall quality of life in comparison to perceived parent's quality of life.

Surveys of current life satisfaction typically show that people worldwide are mostly satisfied with their lives, with mean self-report scores for Western populations at around $75 \%$ of the scale maximum (e.g., Cummins \& Nistico, 2002; Walker, Skowronski \& Thompson, 2003; Roser \& Ortiz-Ospina, 2019). Cummins and Nistico (2002) argue that a generally positive perspective is necessary to endure objective life challenges and to maintain normal functioning. They propose a homeostatic mechanism based on the maintenance of positive cognitive biases. 
In the present study, in addition to assessing current life satisfaction we asked respondents to make a retrospective affective evaluation of their lives comparing their current happiness to one year backward. In short, we focused on the perceived trajectory derived from appraisals of past and present happiness. According to Şimşek (2009), happiness has been understudied from a time perspective. There seems to be predominance of the present, underestimation of the past and a tendency to view the self as an absolute entity. Subjective well-being has been studied from a time perspective, but focusing on the cognitive aspect (Pavot, Diener, \& Suh, 1998; Röcke \& Lachman, 2008). The affective evaluation of life and the relation between affective well-being and life satisfaction in a temporal perspective merits investigation. The temporal self-appraisal theory (TSAT) asserts that individuals tend to evaluate their past selves in a way that makes them feel good about their current selves (Ross \& Wilson, 2003). Since autobiographical memory is a constructive process (Schacter, 2012), they can achieve a positive current self by modifying their past self. Most people assume their lives are continually progressing, from what they have learned from their previous experiences, and that this "core self" they are ever-nearing is intrinsically positive (O’Brien \& Kardas, 2016). Good things about the current self are selectively perceived and prioritized.

In the present study, in addition to assessing their current life satisfaction, and to make a retrospective affective evaluation of their lives, comparing their current happiness to one year backward, we asked respondents to make a retrospective quality of life evaluation using a social yardstick, comparing their current quality of life to their parent's quality of life when they had the same age. Social comparison may be part of a subjective well-being regulation process. According to the theory of social comparison developed by Festinger (1954), people have a need to examine their thoughts and skills in contrast with other people to establish their own position in life. The same may happen regarding well-being.

In a cross-sectional study conducted in the US, Arnett (2000) explored views of the future among young adults aged 21 through 28 asking "Overall, do you think your life is likely to be better or worse than your parents' lives have been?” A majority had an optimistic outlook on the future and regarded their lives would be better $(52 \%)$ or as good (39\%) as their parents' lives. Only 9\% of the respondents believed their lives would be worse than their parents' lives. McBride (2001) analyzed 1994 general social survey (GSS) data comparing their subjective well-being ("Taken all together, how would you say things are these days? Would you say that you are very happy, pretty happy, or not too happy?") compared to their parent's standard of living ("Compared to your parents when they were the age you are now, do you think your own standard of living now is: much better, somewhat better, about the same, somewhat worse, or much worse?"). Respondents who answered that their parents' standard of living was worse than their own reported higher SWB. Those who considered their parents' standard of living was better than their own reported lower SWB. Dufy et al. (2013) examined the extent to which UK population felt that their generation had a better or worse life than their parents' generation by age group: Pre-War born before 1945 (79\% vs 8\%), Baby Boomers born between 1945 and 1965 (70\% vs 14\%), Generation X born between 1966 and 1979 (60 x 19\%), and Generation Y, born between 1980 and 2000 (42\% vs $29 \%$ ). In general, people felt they had a better life than their parents', but the younger generation seemed to be more pessimistic than the others. In a second study, Duffy (2014) found that people from developing countries evaluated they were better off than their parents (e.g., China: 82\%; Brazil: 52\%). The opposite was found among people from developed countries, who apparently feared that their nations' best days were behind them (e.g., French: 25\%; Belgium: 24\%). 


\section{Research questions}

Inspired by the self-appraisal theory and by the notion of ontological well-being we examined subjective well-being considering three aspects: (a) current life satisfaction, (b) retrospective affective self-evaluation and (c) comparison to parents' quality of live. We evaluated socio-demographic correlates (family income, gender, and age) of these three core measures of subjective well-being focusing on broad global judgments made about life as a whole. The examined aspects of subjective well-being may be used as additional measures to understand how people navigate through times of crisis, complementing analyses made with other measures, such as the one presented in the World Happiness Report. We conducted a survey in Brazil before the COVID-19 pandemic (2018) and reapplied the survey at two times (2020 and 2021) during the COVID-19 pandemic. We hypothesized that life satisfaction, happiness and quality of life would be lower during the COVID-19 pandemic than before the pandemic and that the evaluation would become worse from 2020 to 2021 . We also expected to find interaction between the well-being evaluations and the respondents' family income, since there is higher risk of death from COVID-19 among the poorest ( $\mathrm{Li}$ et al., 2021). The number of deaths in Brazil was one of the highest in the world. In June 2020, when we carried out our first data collection during the COVID-19 pandemic, Brazil had reached 29,937 deaths, and by the time of the second data collection the country had reached 325,284 deaths. Despite a solid health infrastructure (SUS), intense political conflicts hindered the arrival of vaccines and the pace of vaccination in the country (da Fonseca, Shadlen, \& Bastos, 2021). In this context, we expected differences of time (before $\mathrm{x}$ during COVID-19 pandemic) on the well-being of our respondents.

\section{METHODS}

\section{Participants and Procedure}

The sample of the study, recruited by a research institute, consisted of 1840 Brazilian adults ( $51.5 \%$ women and $48.5 \%$ men) who answered an online survey before the COVID-19 pandemic in $2018(\mathrm{~N}=616, M=34.46$ years, $S D=8.55)$, and during the pandemic in 2020 $(\mathrm{N}=379, M=33.86$ years, $S D=8.19)$ and in $2021(\mathrm{~N}=845, M=35.73$ years, $S D=8.30)$. The respondents came from the five macro-regions of Brazil (14.5\% North, $24.0 \%$ Northeast, $27.5 \%$ Southeast, $18.6 \%$ South, $15.3 \%$ Center West). An additional sample of 75 respondents with comparable sociodemographic characteristics, recruited by the same research institute, participated at all three times in the survey, before the pandemic of COVID-19 (2018) and during the pandemic (220 and 2021). For details of the sociodemographic characteristics of the respondents see Appendix 1 . The survey was approved (CAAE 80833817.6.0000.5561) by the National Council of Ethics in Research (CONEP) of Brazil.

\section{Measures}

Current life satisfaction

Respondents evaluated their current life satisfaction by a single-item measure "Thinking about your life nowadays, how satisfied are you with your life?" with a 11-point scale from 0 (extremely dissatisfied) to 10 (extremely satisfied). They also answered the Brazilian version of Diener's 5-item Satisfaction with Life Scale (SWLS: e.g., "In most ways my life is close to my ideal") using a 7-point scale that ranged from 1-strongly disagree to 7-strongly 
agree (Diener, Emmons, Larsen \& Griffin, 1985; Zanon, Bardagi, Layous \& Hutz, 2013). The total scale score therefore ranged from 5 to 35 .

Personal retrospective: Self-comparison to one year ago

In addition, we asked respondents to compare how they felt about their lives now with a year ago answering the question "Do you feel happier or less happy nowadays than you did about a year ago?" ( 1 = I feel less happy than last year; 2 = I feel the same, neither more nor less happy than last year; 3 = I feel happier than last year, 4 = I don't know).

Personal retrospective: Comparison to parents' lives

Finally, we asked respondents to compare their lives against the lives of their parents' answering the question "Please compare your life with that of your mother (father) when she (he) was your age. Compared to the life you have nowadays, did she (he) live better, worse or about the same?" ( 1 = When my mother[father] was my age, she[he] lived worse than I do; 2 $=$ When my mother[father] was my age, her[his] life was the same as mine today; $3=$ When my mother[father] was my age, she[he] lived better than I do; 4 = I don't know). There were separate versions of this question according to respondents' gender, so women considered their mothers as references, and men their fathers.

Socio-demographic information and questions about coronavirus

A self-report sociodemographic questionnaire was used to gather information about gender, age, education, marital status, employment status, household monthly income, and region of residence (see Appendix 1). During the pandemic we also asked yes $(=1) /$ no $(=0)$ questions regarding exposition of the respondents and their social network to COVID-19 (see Table 1 below).

\section{Statistical Analyses}

We used one-sample chi-square test and contingency chi-square for categorical data. When the chi-square contingency test values were significant and the levels of the variables examined were greater than two, we examined the values of the adjusted residuals by cell. The standardized residual is found by dividing the difference of the observed and expected values by the square root of the expected value. If the standardized residual is $>+2$ then that cell can be considered to be a major contributor to the overall chi-square value. The adjusted standardized residuals are standardized residuals that are adjusted for the row and column totals.

The total scale score of the Satisfaction with Life Scale (SWLS) and the single-item Life Satisfaction (LS) were analyzed with GLM. For unrelated samples we used a General Linear Model (GLM) MANCOVA to analyze the influence of time $(2018 \times 2020 \times 2021)$, gender (women x men), household income (<2000 x 2000-4000 x 4000-8000 x >8000 Brazilian Real BRL) as fixed factors and age (years) as a covariate on the dependent measures. We used General Linear Model (GLM) Repeated Measures to test the influence of time $(2018 \times 2020 \times 2021)$ on LS and SWLS.

Data analysis was conducted using SPSS Statistics for Windows, Version 28.0 (IBM Corp, Armonk, NY, USA) and Jamovi (Version 1.6). 


\section{RESULTS}

\section{Contact of respondents with covid-19}

It is notable that the contact of respondents and their social network with COVID-19 has increased significantly over time. The comparisons made for all items except one revealed statistically significant differences The percentage of respondents who reported symptoms increased from $13.5 \%$ in 2020 to $26.6 \%$ in 2021 and the percentage of those who were diagnosed increased from $4.5 \%$ to $20 \%$. The proportion of respondents who experienced the death of relatives increased from $4.0 \%$ in 2020 to $15.6 \%$ in 2021 and the proportion of those who experienced the death of close friends and acquaintances increased, respectively, from $8.4 \%$ to $25.6 \%$ and from $34.3 \%$ to $60.7 \%$. Further details can be found in Table 1.

Table 1: Exposure of respondents and their social network to COVID-19

\begin{tabular}{|c|c|c|c|c|c|c|}
\hline \multirow{2}{*}{ ITEMS } & \multicolumn{2}{|c|}{$2020(N=379)$} & \multicolumn{2}{|c|}{$2021(N=845)$} & \multirow{2}{*}{$x^{2}$} & \multirow{2}{*}{ OR 95\% CI } \\
\hline & $\mathbf{n}$ & $\%$ & $\mathbf{n}$ & $\%$ & & \\
\hline \multicolumn{7}{|l|}{ Diagnosis of COVID-19 } \\
\hline diagnosed aquaintances & 179 & 47.2 & 410 & 48.5 & 175 & $1.05(0.83-1.34)$ \\
\hline diagnosed close friend(s) & 112 & 29.6 & 376 & 44.5 & $24.378^{* * *}$ & $1.91(1.48-2.48)$ \\
\hline family member(s) diagnosed & 72 & 19.0 & 421 & 49.8 & $103.353^{* * *}$ & $4.23(3.17-5.66)$ \\
\hline diagnosed respondent & 17 & 4.5 & 169 & 20.0 & $48.870^{* * *}$ & $5.32(3.18-8.91)$ \\
\hline \multicolumn{7}{|l|}{ Symptoms of COVID-19 } \\
\hline acquaintance(s) with symptoms & 162 & 42.7 & 430 & 50.9 & $6.948^{* *}$ & $1.39(1.09-1.77)$ \\
\hline close friend(s) with symptoms & 118 & 31.1 & 396 & 46.9 & $26.575^{* * *}$ & $1.95(1.51-2.52)$ \\
\hline family member(s) with symptoms & 89 & 23.5 & 426 & 50.4 & $77.865^{* * *}$ & $3.31(2.52-4.35)$ \\
\hline respondent with symptoms & 51 & 13.5 & 225 & 26.6 & $25.989^{* * *}$ & $2.33(1.67-3.25)$ \\
\hline \multicolumn{7}{|l|}{ Hospitalization for COVID-19 } \\
\hline hospitalized acquaintance(s) & 144 & 38.0 & 471 & 55.7 & $32.956^{* * *}$ & $2.06(1.60-2.63)$ \\
\hline hospitalized close friend(s) & 63 & 16.6 & 269 & 31.8 & $30.629^{* * *}$ & $2.34(1.72-3.18)$ \\
\hline hospitalized family member(s) & 38 & 10.0 & 224 & 26.5 & $42.252^{* * *}$ & $3.24(2.24-4.68)$ \\
\hline hospitalized respondent & 1 & 0.3 & 24 & 2.8 & $8.680^{* *}$ & $11.05(1.49-81.98)$ \\
\hline \multicolumn{7}{|l|}{ Death from COVID-19 } \\
\hline death of acquaintance(s) & 130 & 34.3 & 513 & 60.7 & $73.182^{* * *}$ & $2.96(2.30-3.81)$ \\
\hline death of close friend(s) & 32 & 8.4 & 216 & 25.6 & $47.460^{* * *}$ & $3.72(2.51-5.52)$ \\
\hline death of family member(s) & 15 & 4.0 & 132 & 15.6 & $33.682^{* * *}$ & $4.49(2.60-7.78)$ \\
\hline
\end{tabular}

Note: ${ }^{*} \mathrm{p}<0.05,{ }^{* *} \mathrm{p}<0.01,{ }^{* * *} \mathrm{p}<0.001 ;$ OR $=$ Odds Ratio, $95 \% \mathrm{CI}=95 \%$ confidence interval

\section{Current satisfaction with life}

Contrary to our expectation, the GLM analysis performed with the independent samples did not reveal a main effect of time (before and during covid-19) on the single-item question life satisfaction (LS) scores $\left[\mathrm{F}(2,1522)=0.022, \mathrm{p}=0.979, \eta \mathrm{p}^{2}=0.000\right]$. The 
means were 6.29 with a $95 \%$ confidence interval of 6.10 to 6.48 in $2018,6.25$ with a $95 \%$ CI of 6.00 to 6.49 in 2020, and 6.40 with a $95 \%$ CI of 6.24 to 6.56 in 2021. However significant main effects for household income $\left[\mathrm{F}(3,1522)=4.530, \mathrm{p}=0.04, \eta \mathrm{p}^{2}=0.01\right]$ and gender $\left[\mathrm{F}(1,1522)=4.024, \mathrm{p}=0.045, \eta \mathrm{p}^{2}=0.003\right]$ were found on LS. There were no significant effect of the covariate age $\left[\mathrm{F}(1,1522)=1.687, \mathrm{p}=0.194, \eta \mathrm{p}^{2}=0.001\right]$ nor interaction effects [Time $x$ Family income $F(6,1522)=0.318, p=0.928, \eta p^{2}=0.001$; Time $x$ Gender $\mathrm{F}(2,1522)=0.004, \mathrm{p}=0.996, \eta \mathrm{p}^{2}=0.000$, Time $\mathrm{x}$ Family income $\mathrm{x}$ Gender $(\mathrm{F} 6,1522)=$ $\left.0.479, \mathrm{p}=0.824, \eta \mathrm{p}^{2}=0.002\right]$. As can be seen in Figure 1, satisfaction with life scores increased with increasing income. Post hoc comparisons using the Tukey B test indicated that the mean life satisfaction scores for family incomes $>2000 \mathrm{BRL}(2000-4000 \mathrm{M}=6.44$, 95\% CI 6.24-6.64; 4000-8000 $\mathrm{M}=6.55,95 \%$ CI 6.30-6.79; $>8000 \mathrm{M}=6.6995 \% \mathrm{CI}$ 6.38-6.99) were significantly higher than those in the $<2000 \mathrm{BRL}$ condition $(\mathrm{M}=5.95,95 \%$ CI 5.73-6.18). Regarding gender, women $(M=6.25$, 95\% CI 6.02-6.48) had slightly lower LS scores than men $(M=6.57,95 \%$ CI 6.36-6.79).
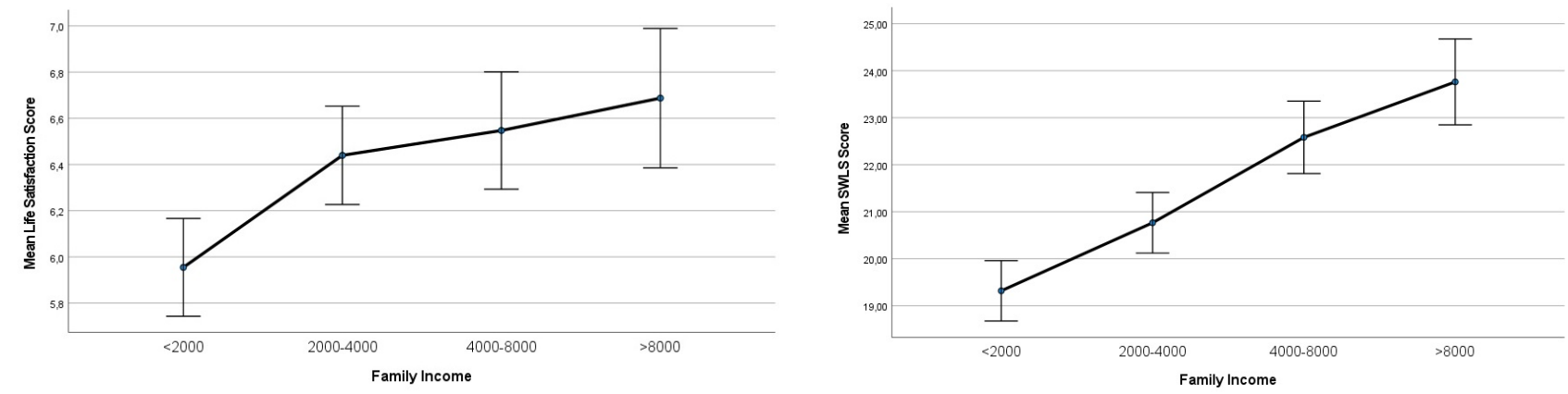

Figure 1: Mean Life Satisfaction and SWLS scores as a function of household income. Error bars indicate $95 \% \mathrm{CI}$ (confidence interval).

Also considering the independent samples, another GLM analysis focusing on the total SWLS scores failed to reveal a significant time effect $\left[\mathrm{F}(2,1522)=0.496, \mathrm{p}=0.609, \eta \mathrm{p}^{2}=\right.$ 0.001 ]. The means were 20.63 with a $95 \%$ confidence interval of 20.06 to 21.20 in 2018, 20.56 with a $95 \%$ CI of 19.83 to 21.30 in 2020 , and 21.72 with a $95 \%$ CI of 21.21 to 22.23 in 2021. This analysis also revealed a significant main effect for household income on total SWLS scores $\left[\mathrm{F}(3,1522)=15.085, \mathrm{p}=0.001, \eta \mathrm{p}^{2}=0.03\right]$. No main effects were found for gender $\left[\mathrm{F}(1,1522)=1.366, \mathrm{p}=0.243, \eta \mathrm{p}^{2}=0.001\right]$, the covariate age $[\mathrm{F}(2,1522)=2.938$, $\mathrm{p}=0.087, \eta \mathrm{p}^{2}=0.002$ ], or interaction effects [Time $\mathrm{x}$ Family income $\mathrm{F}(6,1522)=0.097, \mathrm{p}$ $=0.997, \eta \mathrm{p}^{2}=0.000$; Time $\mathrm{x}$ Gender $\mathrm{F}(2,1522)=0.258, \mathrm{p}=0.773, \eta \mathrm{p}^{2}=0.000$, Time $\mathrm{x}$ Family income $x$ Gender $\left.(F 6,1522)=1.557, p=0.156, \eta p^{2}=0.006\right]$. As can be seen in Figure 1, the higher the income, the higher the total SWLS scores. Post hoc comparisons using the Tukey B test indicated that the mean SWLS score for the $>8000 \mathrm{BRL}(\mathrm{M}=23.76$, 95\% CI 22.87-24.65) and the 4000-8000 BRL ( $\mathrm{M}=22.58$, 95\% CI 21.86-23.31) family incomes were significantly higher than the 2000-4000 BRL family income ( $M=20.77,95 \%$ CI 20.13-21.40) which was higher than the $<2000 \mathrm{BRL}$ family income $(\mathrm{M}=19.32,95 \% \mathrm{CI}$ 18.63-20.00).

Among the resampled respondents $(\mathrm{N}=75)$ analyses performed by Repeated Measures GLM revealed that there were no significant effects of time on the life satisfaction scores [F $(2,73)=1.799, \mathrm{p}=0.173, \eta \mathrm{p} 2=0.047]$ or on the total SWLS scores $[\mathrm{F}(2,73)=0.312, \mathrm{p}=$ $0.733, \eta \mathrm{p} 2=0.008]$. The mean life satisfaction (LS) single item scores during the 
COVID-19 pandemic were 6.41 (95\% CI 5.81-7.02) in 2020 and 6.59 (95\% CI 6.07-7.11) in 2021, compared to 6.11 (95\% CI 5.54-6.67) before the pandemic in 2018. The mean SWLS scores during the COVID-19 pandemic were 20.20 (95\% CI 18.60-21.79) in 2020 and 20.40 (95\% CI 18.77-22.03) in 2021, compared to 19.84 (95\%CI 18.01-21.67) before the pandemic in 2018.

\section{Personal retrospective: Comparison to parents' lives}

In all the samples, irrespectively of time, most respondents reported their parents lived worse than them (Table 2). A positive outlook on life of the respondents, evaluating their quality of life better than that of their parents when they were the same age as them, predominated in our samples, both before the COVID-19 pandemic and during the pandemic.

Table 2: Perceived parents' quality of life (IS=Independent Sample, DS=Dependent Sample).

\begin{tabular}{|c|c|c|c|c|c|c|c|c|c|c|c|c|}
\hline & \multicolumn{2}{|c|}{$\begin{array}{c}2018 \\
\text { IS }\end{array}$} & \multicolumn{2}{|c|}{$\begin{array}{c}2020 \\
\text { IS }\end{array}$} & \multicolumn{2}{|c|}{$\begin{array}{c}2021 \\
\text { IS }\end{array}$} & \multicolumn{2}{|c|}{$\begin{array}{c}2018 \\
\text { DS }\end{array}$} & \multicolumn{2}{|c|}{$\begin{array}{c}2020 \\
\text { DS }\end{array}$} & \multicolumn{2}{|c|}{$\begin{array}{c}2021 \\
\text { DS }\end{array}$} \\
\hline & $\mathrm{n}$ & $\%$ & $\mathrm{n}$ & $\%$ & $\mathrm{n}$ & $\%$ & $\mathrm{n}$ & $\%$ & $\mathrm{n}$ & $\%$ & $\mathrm{n}$ & $\%$ \\
\hline worse & 302 & 64.8 & 227 & 73.9 & 475 & 66.5 & 42 & 73.7 & 43 & 75.4 & 44 & 77.2 \\
\hline equal & 62 & 13.3 & 35 & 11.4 & 107 & 15.0 & 10 & 17.5 & 8 & 14.0 & 6 & 10.5 \\
\hline better & 102 & 21.9 & 45 & 14.7 & 132 & 18.5 & 5 & 8.8 & 6 & 10.5 & 7 & 12.3 \\
\hline $\mathrm{N}$ & 466 & 100 & 307 & 100 & 714 & 100.0 & 57 & 100.0 & 57 & 99.9 & 57 & $\begin{array}{l}100 \\
0\end{array}$ \\
\hline$\chi^{2}(\mathrm{df}=2)$ & $\begin{array}{c}212 \\
\mathrm{p}=\mathrm{C}\end{array}$ & & $\begin{array}{l}228 \\
p=0\end{array}$ & $\begin{array}{l}300 \\
.001\end{array}$ & $\begin{array}{l}355 \\
\mathrm{p}=\end{array}$ & $\begin{array}{l}319 \\
.001\end{array}$ & $\begin{array}{r}42 \\
\mathrm{p}=0\end{array}$ & $\begin{array}{l}421 \\
.001\end{array}$ & $\begin{array}{r}45 \\
\mathrm{p}=0\end{array}$ & $\begin{array}{l}79 \\
.001\end{array}$ & $\begin{array}{r}49.3 \\
p=0\end{array}$ & $\begin{array}{l}68 \\
.001\end{array}$ \\
\hline
\end{tabular}

The Satisfaction with Life Scale (SWLS) scores were significantly associated with the evaluation of parents' quality of life (worse $\mathrm{x}$ equal $\mathrm{x}$ better) among respondents of each of the three samples, before and during the COVID-19 pandemic (Table 3). Subscripts were used to indicate pairwise comparisons and whether such comparisons were statistically different. Mean values with different subscript letters in a column were significantly different. In addition to mean values each cell shows $95 \%$ confidence interval. As can be seen from Table 3, these pairwise comparisons revealed that respondents who perceived their parents as living worse than them or the same scored higher on the SWLS than those who considered that their parents lived better than them. Considering the single-item question of current life satisfaction, the same significant association was found with the retrospective assessment of parents' quality of life. Post hoc tests revealed that respondents who perceived their parents as living worse than them or the same scored higher on current life satisfaction than those who considered their parents lived better than them. 
Table 3: SWLS and Single-item current life satisfaction (LS) scores as a function of perception of parent's quality of life for each of the independent three samples.

\begin{tabular}{|c|c|c|c|}
\hline \multicolumn{4}{|c|}{ SWLS } \\
\hline Evaluation & 2018 & 2020 & 2021 \\
\hline worse & $\begin{array}{l}21.31_{\mathrm{a}} \\
20.51-22.10\end{array}$ & $\begin{array}{l}21.37 \mathrm{a} \\
20.47-22.27\end{array}$ & $\begin{array}{l}22.17 a \\
21.51-22.84\end{array}$ \\
\hline equal & $\begin{array}{l}20.31_{a, b} \\
18.55-22.06\end{array}$ & $\begin{array}{l}21.69 \mathrm{a} \\
19.39-23.98\end{array}$ & $\begin{array}{l}23.86_{a} \\
22.46-25.26\end{array}$ \\
\hline better & $\begin{array}{l}18.44 \mathrm{~b} \\
17.07-19.81\end{array}$ & $\begin{array}{l}18.33_{b} \\
16.31-20.36\end{array}$ & $\begin{array}{l}18.73_{b} \\
17.47-19.99\end{array}$ \\
\hline F statistic and $p$ value & $\begin{array}{l}F(2,463)=6.358 \\
p=0.002\end{array}$ & $\begin{array}{l}\mathrm{F}(2,304)=3.859 \\
\mathrm{p}=0.022\end{array}$ & $\begin{array}{l}F(2,711)=16.84 \\
p=0.001\end{array}$ \\
\hline effect size & $\eta \mathrm{p}^{2}=0.03$ & $\eta p^{2}=0.03$ & $\eta p^{2}=0.04$ \\
\hline \multicolumn{4}{|c|}{ LS } \\
\hline worse & $\begin{array}{l}6.54 a \\
6.27-6.80\end{array}$ & $\begin{array}{l}6.41_{\mathrm{a}, \mathrm{b}} \\
6.11-6.70\end{array}$ & $\begin{array}{l}6.63 a \\
6.41-6.84\end{array}$ \\
\hline equal & $\begin{array}{l}6.45 \mathrm{a} \\
5.88-7.03\end{array}$ & $\begin{array}{l}6.80_{a} \\
6.04-7.56\end{array}$ & $\begin{array}{l}6.91_{a} \\
6.46-7.35\end{array}$ \\
\hline better & $\begin{array}{l}5.37 \mathrm{~b} \\
4.92-5.82\end{array}$ & $\begin{array}{l}5.71_{b} \\
5.04-6.38\end{array}$ & $\begin{array}{l}5.36_{b} \\
4.91-5.81\end{array}$ \\
\hline F statistic and $p$ value & $\begin{array}{l}F(2,463)=9.915 \\
p=0.001\end{array}$ & $\begin{array}{l}F(2,304)=2.50 \\
p=0.083\end{array}$ & $\begin{array}{l}\mathrm{F}(2,711)=17.278 \\
\mathrm{p}=0.001\end{array}$ \\
\hline effect size & 0.04 & 0.02 & $\eta p^{2}=0.05$ \\
\hline
\end{tabular}

Additional analyses of the perception of parent's quality of life were then made as a function of sociodemographic variables, based on the independent samples taken together (Appendix 2). A significant association was found between this perception and gender. Women were more likely than men to report that their mothers lived worse than them. There was also a significant association between respondents' age and their perception of parent's quality of life. Younger respondents (18-30 years) were more likely than older respondents, in the age ranges (31-40, 41-50 and $>50$ years), to consider that their parents lived worse than them. Older respondents (41-50 and $>50$ years) were more likely to evaluate that their parents lived better than them. No significant association was identified between perception of parent's quality of life and household income

\section{Personal retrospective: Self-comparison to one year ago}

One sample chi-square tests showed that most respondents reported they felt happier than last year or the same in our independent samples. Among the respondents of the repeated measures sample the evaluations were more evenly distributed across the response categories irrespectively of time (Table 4).

However, in the independent samples, it is notable that proportions changed over time. A contingency chi-square test showed a significant association of respondents' evaluation and time (before and during the COVID-19 pandemic), $\chi^{2}(4 \mathrm{df})=23.650, \mathrm{p}=0.001$. High positive adjusted residuals $(>2)$ indicated that before the COVID-19 outbreak (2018) there 
were more respondents who perceived themselves happier in comparison with the last year than expected, adjusted for sample size (adjusted residual = 3.5). At the peak of the COVID-19 pandemic (2021) there were more respondents who perceived themselves less happy in comparison with the last year than expected, adjusted for sample size (adjusted residual $=3.4$ ).

Table 4: Perceived happiness one year ago (IS=Independent Sample, DS=Dependent Sample).

\begin{tabular}{|c|c|c|c|c|c|c|c|c|c|c|c|c|}
\hline & \multicolumn{2}{|c|}{$\begin{array}{c}2018 \\
\text { IS }\end{array}$} & \multicolumn{2}{|c|}{$\begin{array}{c}2020 \\
\text { IS }\end{array}$} & \multicolumn{2}{|c|}{$\begin{array}{c}2021 \\
\text { IS }\end{array}$} & \multicolumn{2}{|c|}{$\begin{array}{c}2018 \\
\text { DS }\end{array}$} & \multicolumn{2}{|c|}{$\begin{array}{c}2020 \\
\text { DS }\end{array}$} & \multicolumn{2}{|c|}{$\begin{array}{c}2021 \\
\text { DS }\end{array}$} \\
\hline & $\mathrm{n}$ & $\%$ & $\mathrm{n}$ & $\%$ & $\mathrm{n}$ & $\%$ & $\mathrm{n}$ & $\%$ & $\mathrm{n}$ & $\%$ & $\mathrm{n}$ & $\%$ \\
\hline happier & 261 & 44.8 & 155 & 41.9 & 273 & 33.6 & 17 & 26.2 & 22 & 33.8 & 19 & 29.2 \\
\hline equal & 203 & 34.8 & 122 & 33.0 & 301 & 37.1 & 30 & 46.2 & 24 & 36.9 & 29 & 44.6 \\
\hline Less happy & 119 & 20.4 & 93 & 25.1 & 238 & 29.3 & 18 & 27.7 & 19 & 29.2 & 17 & 26.2 \\
\hline $\mathrm{N}$ & 583 & 100 & 370 & 100 & 812 & 100 & 65 & 100.1 & 65 & 100 & 65 & 100 \\
\hline$\chi^{2}(\mathrm{df}=2)$ & $\begin{array}{l}52.460 \\
\mathrm{p}=0.0\end{array}$ & & $\begin{array}{l}15.6 \\
p=c\end{array}$ & $\begin{array}{l}05 \\
.001\end{array}$ & $\begin{array}{l}7.362 \\
p=0.02\end{array}$ & & $\begin{array}{l}4.831 \\
p=0.08\end{array}$ & & $\begin{array}{l}0.585 \\
p=0.74\end{array}$ & & $\begin{array}{l}3.815 \\
p=.148\end{array}$ & \\
\hline
\end{tabular}

Scores on the Satisfaction with Life Scale (SWLS) were significantly associated with the perceived happiness one year ago in the independent samples [ANOVA: $F(2,1762)=$ 93.000, $\mathrm{p}<0.001, \eta \mathrm{p} 2=0.095]$. Post hoc Tukey B tests revealed that respondents who reported greater happiness in comparison to one year ago scored higher on the SWLS ( $M=$ 23.60, 95\% CI: 23.12-24.08 ) than those who reported they were less happy now ( $\mathrm{M}=$ 17.79 , 95\% CI: 17.09-18.50 ). Those who perceived no difference were situated in an intermediate position ( $M=20.94,95 \% \mathrm{CI}: 20.37-21.52)$. Considering the single-item question of current life satisfaction (LS) the same significant association was found with the retrospective perception of happiness one year ago that had been found regarding SWLS [ANOVA: $\left.\mathrm{F}(2,1762)=97.362, \mathrm{p}<0.001, \eta \mathrm{p}^{2}=0.095\right]$. Post hoc Tukey B tests revealed that respondents who perceived they were happier than one year ago $(\mathrm{M}=7.14,95 \% \mathrm{CI}$ : 6.98-7.30 ) scored higher in current life satisfaction than those who considered they were less happy than one year ago $(M=5.22,95 \% \mathrm{CI}: 4.98-5.46)$. On LS respondents who reported that their happiness did not change were in an intermediate position $(M=6.27$, 95\% CI: 6.10-6.45).

Additional analyses on the self-comparison to one year ago were then made as a function of sociodemographic variables, based on the independent samples taken together (Appendix 3). No significant association was found between perceived happiness one year ago and household income $\left[\chi^{2}(6 \mathrm{df})=7.278, \mathrm{p}=0.296\right]$ nor gender $\left[\chi^{2}(2 \mathrm{df})=3.698, \mathrm{p}\right.$ $=0.157]$. However, a significant association was found between perceived happiness one year ago and age $\left[\chi^{2}(6 \mathrm{df})=34.376, \mathrm{p}=0.001\right]$. High positive adjusted residuals $(>2)$ indicated that in the younger age range (18-30) there were more respondents who perceived themselves happier in comparison with the last year than expected, adjusted for sample size (adjusted residual $=4.0$ ). In the age range 31-40 there were more respondents who perceived themselves less happy in comparison with the last year than expected, adjusted for sample size (adjusted residual $=3.8$ ). In the age range $41-50$ there were 
proportionally more respondents who perceived themselves equally happy in comparison with the last year, adjusted for sample size (adjusted residual $=3.4$ ).

\section{DISCUSSION}

In the present study, no differences were found as a function of the timing of the survey in all but one of the subjective well-being measures taken. Contrary to our initial expectations we found no statistically significant differences, either in the independent samples or in the dependent sample, before or during the COVID-19 pandemic, in life satisfaction as measured by the five-item life satisfaction scale (SWLS) or the one-item current life satisfaction question (LS). Additionally, no difference was found as a function of time in the measure involving personal retrospective in which respondents were asked to compare their quality of life to that of their parents when they were the same age as them. These were unexpected findings because the world was facing an unprecedented health crisis that threatened people's lives, and Brazil was one of the worst affected countries of the world in number of COVID-19 cases and deaths. But it is also notable that the World Happiness Report, despite reporting changes such as Brazil's drop from position 29 to position 41 out of 95 countries, the change was found in decimals from mean score 6.376 (95\% CI 6.296-6.456) in 2018 to mean score 6.110 (95\% CI 5.888-6.332) in 2020. Helliwell, Huang, Wang and Norton (2021) called attention to the fact that the report showed that COVID-19 has led to relatively modest changes in the overall rankings, reflecting a generally shared resilience in the face of the pandemic.

In the current study, of all the analyses carried out, only one statistically significant difference has been found as a function of time using a contingency chi-square. The percentages of respondents who perceived themselves happier in comparison with the last year diminished from $44.8 \%$ in 2018 to $41.9 \%$ in 2020 and $33.6 \%$ in 2021 . Respondents who perceived themselves less happy in comparison with the last year increased from $20.4 \%$ in 2018 to $25.1 \%$ in 2020 and $29.3 \%$ in 2021 . Absence of change was reported by $34.8 \%$ of the respondents in 2018, 33.0\% in 2020, and 37.1\% in 2021. Analysis of adjusted residuals showed that the observed frequencies were different from the expected frequencies adjusted for sample size at the extremes (happier in 2018 and less happy in 2021).

In the present study, when asked to rate their current overall life satisfaction on a scale from 0 (extremely dissatisfied) to 10 (extremely satisfied), respondents gave averages of 6.29 in 2018, 6.25 in 2020, and 6.40 in 2021 broadly in line with the Brazilians' average of 6.40 reported by the Organization for Economic Co-operation and Development (OECD, 2018), and the averages of 6.38 in 2018 and 6.11 in 2020 reported in the World Happiness Report (Helliwell et al., 2021). There was a clustering of scores at around three-quarters of the measurement scale maximum as has been reported for Western and non-Western countries before the pandemic (e.g., Cummins \& Nistico, 2002; Cummins \& Lau, 2011; Selin \& Davey, 2012). This predominant positivity is compatible with an interpretation based on an underlying homeostatic mechanism for life satisfaction controlled by positive cognitive biases pertaining to the self (Capic, Li \& Cummins, 2018; Sharot, 2011) and also by hedonic adaptation (Lyubomirsky, 2011; Luhmann \& Intelisano, 2018). There is a vast scientific literature (for a review, see Walker \& Skowronski, 2009) showing that the fading affect bias is a robust effect in autobiographical memory. The intensity of negative affect associated with autobiographical memories fades faster than the intensity of positive affect associated with autobiographical memories. 
In the present study, similar patterns of results were obtained both with the one-item question of current life satisfaction (LS) and the composite Satisfaction with Life Scale (SWLS), a widely used measure to evaluate subjective well-being (Diener, Emmons, Larsen \& Griffin, 1985; Zanon, Bardagi, Layous \& Hutz, 2013). Of the socio-demographic variables examined (household income, gender, and age), the household income was significantly associated with LS and SWLS. Respondents with higher household income exhibited higher mean levels of current life satisfaction. This finding was expected considering the range of income to allow individuals to fulfill decent living standards. A ceiling effect of income on life satisfaction once an individual reaches a relatively high income as found in more economically developed countries (e.g., Kahneman \& Deaton, 2010) was not expected in our samples.

Respondents' positive outlook on life was evidenced by their personal retrospectives, by the self-comparison to one year ago but most clearly by comparison to parents' lives. Our findings showed that they compared themselves to their parents in a way to feel better about themselves. Our findings are in line with what we expected based on Duffy's (2014) survey, for people of a developing country. In this survey, a clear dividing line was found between developing and developed countries. Adults in developing countries were more optimistic than their counterparts in rich countries. Differently from Duffy et al. (2013), in our study we found that respondents in the younger age range were more optimistic than respondents in the older age ranges.

We also found a significant gender effect. Women had slightly lower LS scores than men. In addition, women had a higher chance of considering their mothers lived worse than them in comparison to men. This finding may be explained in terms of aspiration adjustment, based on Inglehart (2002). There may have been a relative improvement in the position of Brazilian women as a generational trend. Starting from positions of relatively great deprivation, women may have made substantial strides toward gender equality from a generation to the next. Even though society may not be fully egalitarian, women may have experienced an upward shift, raising their perceived situation relative to their aspiration level.

The more positive the outlook on life, in the personal retrospectives both by comparison to parents' lives and by the self-comparison to one year ago, the higher the reported level of current life satisfaction (LS and SWLS). These findings are in line with results from McBride (2001) based on the 1994 US general social survey data. Respondents who evaluated that their parents' standard of living was worse than their own reported higher SWB, whereas those who evaluated that their parents' standard of living was better than their own reported lower SWB.

\section{Conclusion and Future Directions}

Our samples were composed of Brazilian adults with access to computer/tablet for internet use, balanced with respect to sex, age, social classes (A, B1, B2, C1, C2), and demographic regions of the country. In future studies, we intend to expand the survey to include other age groups and social classes $\mathrm{D}$ and $\mathrm{E}$.

As expected by the self-appraisal theory we found positively biased appraisals in all these three facets of subjective well-being studied. We agree with Cummins and Nistico (2002) that there is a general human tendency toward positivity, based on the maintenance of positive cognitive biases. We also agree with Sheldon, Boehm and Lyubomirsky (2013), who claim that this positivity trend is an adaptive characteristic of human nature that helps people recover from the slings and arrows of lived experiences. According to the neuroscientist Sharot (2011), the human brain has a built-in optimism bias. We are wired by evolution to see the glass half-full. Optimism biases could benefit their holders contributing 
to their success through a self-fulfilling prophecy mechanism. There is evidence that positivity bias is associated to physical well-being, healthy lifestyle (e.g., Conversano et al., 2010) and longevity (e.g., Lee et al., 2019).

One interesting direction for further research is to investigate the imagination of the personal future and the constructive nature of memory (e.g., Szpunar, Addis, \& Schacter, 2012). Whereas researchers have traditionally studied memory with a focus on the past, recent research has led to the concept of prospective brain, showing that imagining the future depends to a large extent on the same neural network involved in remembering the past (Schacter et al., 2007). This is an adaptive cognitive process because it allows flexible use of information from the past in the simulation of alternative future scenarios without performing overt actions, but at the expense of susceptibility to inaccuracies that result from the combination of components of imagination and memory.

Positivity biases could have costs, but the costs were outweighed by the benefit in the selection of this mechanism during human evolution. We were able to resignify negative experiences, diminishing their impact and seeing more favorable prospects for the future. Positivity is encouragement to move forward. Although positivity bias seems puzzling at first sight it may have evolved because it has favorably impacted fitness. Johnson and Fowler (2007) developed a computational model, adapted from the Hawk-Dove model of game theory, showing that overestimating personal success probabilities would be advantageous on average (even if costly at times) in an environment of uncertainty and competition, increasing net payoffs. According to this model, if the benefits of disputed resources were sufficiently large compared to the costs of competing for them, humans would have evolved a bias to overestimate their probability of success over the course of human evolutionary history.

Individuals suffering from depression do not present this positivity bias. Strunk et al. (2006) showed that healthy humans tend to expect the future to be slightly better than it turns out, whereas people with moderate depression do not exhibit this bias and people with severe depression tend to expect things to be worse than they end up being. When envisioning their future, healthy people tend to build positively biased scenarios, imagining positive happenings in more detail and closer in time than negative happenings. Mentally, people move toward positive future scenarios and away from negative future scenarios (Sharot, 2011). The nature of future-directed thinking, emotion and memory of patients with affective disorders would be of interest in addition to non-clinical populations.

\section{FUNDING}

We acknowledge funding by No. 2014/50282-5, and 2017/11748-7 from the São Paulo Research Foundation (FAPESP) and Natura Cosméticos S.A. and grant No. 304740/2017-9 from the Brazilian National Research Council (CNPq).

\section{CONFLICT OF INTEREST AND TRANSPARENCY}

The authors declare no competing interests. The data set analyzed and presented in the current study is available from the corresponding author on reasonable request.

\section{ETHICAL STATEMENT}

The study was conducted with the approval of the Research Ethics Committee on Human Beings (no: 80833817.6.0000.5561).

\section{ACKNOWLEDGEMENT}

We wish to thank Professor Fernando Leite Ribeiro for his invaluable contribution to the 
development of the survey. We would also like to thank the anonymous reviewers for their constructive comments and suggestions that improved the paper. Any remaining mistakes are our own.

\section{AUTHOR CONTRIBUTIONS}

VSRB and EO designed the study. RPF, VFD and EO analyzed the data. RDF provided the original draft of the manuscript. All authors contributed to writing and editing and approved the manuscript for its intellectual content.

\section{REFERENCES}

Arnett, J. J. (2000). High hopes in a grim world: emerging adults' views of their futures and "Generation X". Youth \&" Society, 31 (3), 267-286. DOI

Bartels, M. (2015). Genetics of well-being and its components: satisfaction with life, happiness, and quality of life: A review and meta-analysis of heritability studies. Behavior Genetics, 45 (2), 137-156. DOI

Capic, T., Li, N., \& Cummins, R. A. (2018). Confirmation of subjective wellbeing set-points: Foundational for subjective social indicators. Social Indicators Research, 137(1), 1-28. DOI

Conversano, C., Rotondo, A., Lensi, E., Della Vista, O., Arpone, F., \& Reda, M. A. (2010). Optimism and its impact on mental and physical well-being. Clinical practice and epidemiology in mental health: $C P$ \& $E M H, 6,25$. DOI

Cummins, R. A. \& Nistico, H. (2002). Maintaining life satisfaction: the role of positive cognitive bias. Journal of Happiness Studies, 3 (1), 37-69. DOI

Cummins, R. A. \& Lau, A. L. D. (2011). Well-being across cultures issues of measurement and the interpretation of data. In Kenneth D. Keith (ed). Cross-Cultural Psychology Contemporary Themes and Perspectives. UK: Wiley-Blackwell.

da Fonseca, E. M., Shadlen, K. C., \& Bastos, F. I. (2021). The politics of COVID-19 vaccination in middle-income countries: Lessons from Brazil. Social Science \& Medicine, 114093. DOI

Deci, E. L. \& Ryan, R. M. (2008). Hedonia, eudaimonia, and well-being: an introduction. Journal of Happiness Studies, 9 (1), 1-11.

Diener E., Emmons R., Larsen R. J., \& Griffin S. (1985). The Satisfaction with Life Scale. Journal of Personality Assessment, 49, 71-75. DOI

Diener, E., \& Lucas, R. E. (1999). Personality and subjective well-being. In Daniel Kahneman, Edward Diener, Norbert Schwarz (eds.) Well-being: Foundations of hedonic psychology, pp. 213-229. New York: Russell Sage.

Diener, E., Suh, E. M., Lucas, R. E., \& Smith, H. L. (1999). Subjective well-being: Three decades of progress. Psychological Bulletin, 125 (2), 276-302. DOI

Duffy, B., Hall, S., O'Leary, D. \& Pope, S. (2013). Generation Strains, a Demos and Ipsos MORI report on changing attitudes to welfare. London: Demos.

Duffy, B. (2014). Ipsos MORI Global Trends Survey. London: Demos

Festinger, L. (1954). A theory of social comparison processes. Human Relations, 7 (2), 117-140. DOI

Grinde, B. (2012). The biology of happiness. Springer Science \& Business Media.

Helliwell, J. F., Huang, H., Wang, S. \& Norton, M. (2021). Happiness, trust, and death under covid-19. In Helliwell, John F., Richard Layard, Jeffrey Sachs, and Jan-Emmanuel De Neve (eds.). World Happiness Report 2021. New York: Sustainable Development Solutions Network.

Huebner, E. S. (1991). Initial development of the student's life satisfaction scale. School Psychology International, 12 (3), 231-240. DOI

Inglehart, R. (2002). Gender, aging, and subjective well-being. International Journal of Comparative Sociology, 43(3-5), 391-408. DOI 
Johnson, D.D.P, and Fowler, H.F. (2011). The evolution of overconfidence. Nature, 477, 317-320. $\underline{\mathrm{DOI}}$

Karwowski, M., Kowal, M., Groyecka, A., Białek, M., Lebuda, I., Sorokowska, A., \& Sorokowski, P. (2020). When in Danger, Turn Right: COVID-19 Threat Promotes Social Conservatism and Right-wing Presidential Candidates. Human Ethology, 35, 37-48. DOI

Kenrick, D. T., \& Krems, J. A. (2018). Well-being, self-actualization, and fundamental motives: An evolutionary perspective. In E. Diener, S. Oishi, \& L. Tay (Eds.), Handbook of well-being. Salt Lake City, UT: DEF Publishers.

Kahneman, D. \& Deaton, A. (2010). High income improves evaluation of life but not emotional wellbeing. Proceedings of the National Academy of Sciences, 107 (38), 16489-16493. DOI

Lee, L. O., James, P., Zevon, E. S., Kim, E. S., Trudel-Fitzgerald, C., Spiro, A., ... \& Kubzansky, L. D. (2019). Optimism is associated with exceptional longevity in 2 epidemiologic cohorts of men and women. Proceedings of the National Academy of Sciences, 116(37), 18357-18362. DOI

Li, S. L., Pereira, R. H., Prete Jr, C. A., Zarebski, A. E., Emanuel, L., Alves, P. J., ... \& Messina, J. P. (2021). Higher risk of death from COVID-19 in low-income and non-White populations of São Paulo, Brazil. BMJ global health, 6(4), e004959. DOI

Luhmann, M., \& Intelisano, S. (2018). Hedonic adaptation and the set point for subjective wellbeing. In E. Diener, S. Oishi, \& L. Tay (Eds.), Handbook of well-being. Salt Lake City, UT: DEF Publishers.

Lyubomirsky, S. (2011). Hedonic adaptation to positive and negative experiences. In S. Folkman (Ed.), Oxford library of psychology. The Oxford handbook of stress, health, and coping ( $\mathrm{p}$. 200-224). Oxford University Press.

McBride, M. (2001). Relative-income effects on subjective well-being in the cross-section. Journal of Economic Behavior \& Organization, 45 (3), 251-278. DOI

O'Brien, E. \& Kardas, M. (2016). The Implicit Meaning of (My) Change. Journal of Personality and Social Psychology, 111(6), 882-894. DOI

OECD. Organization for Economic Cooperation and Development (2013). Health at a glance 2013: $O E C D$ indicators. OECD publishing.

OECD. Organization for Economic Cooperation and Development (2018). Health at a glance: Europe 2018. OECD publishing.

Pavot, W., Diener, E., \& Suh, E. (1998). The temporal satisfaction with life scale. Journal of Personality Assessment, 70(2), 340-354. DOI

Röcke, C., \& Lachman, M. E. (2008). Perceived trajectories of life satisfaction across past, present, and future: Profiles and correlates of subjective change in young, middle-aged, and older adults. Psychology and Aging, 23(4), 833-847. DOI

Roser, M. \& Ortiz-Ospina, E. (2019). Income Inequality. Published online at OurWorldInData.org. Retrieved from: https://ourworldindata.org/income-inequality' [Online Resource].

Ross, M., \& Wilson, A. E. (2003). Autobiographical memory and conceptions of self: Getting better all the time. Current Directions in Psychological Science, 12(2), 66-69. DOI

Schacter, D. L. (2012). Constructive memory: past and future. Dialogues in Clinical Neuroscience, 14(1), 7-18. DOI

Seitz, B. M., Aktipis, A., Buss, D. M., Alcock, J., Bloom, P., Gelfand, M., ... \& Haselton, M. G. (2020). The pandemic exposes human nature: 10 evolutionary insights. Proceedings of the National Academy of Sciences, 117(45), 27767-27776. DOI

Selin, H. \& Davey, G. (2012). Happiness across cultures: views of happiness and quality of life in nonWestern cultures. New York: Springer.

Sharot, T. (2011). The optimism bias. Current biology, 21(23), R941-R945. DOI

Sheldon, K. M., Boehm, J. \& Lyubomirsky, S. (2013). Variety is the spice of happiness: The hedonic adaptation prevention model. Oxford Handbook of Happiness, 901-914. DOI

Şimşek, Ö. F. (2009). Happiness revisited: Ontological well-being as a theory-based construct of subjective well-being. Journal of Happiness Studies, 10(5), 505-522. DOI

Szpunar, K. K., Addis, D. R., \& Schacter, D. L. (2012). Memory for emotional simulations: Remembering a rosy future. Psychological Science, 23(1), 24-29. DOI 
Stiglitz, J. E., Sen, A., \& Fitoussi, J. P. (2009). Report by the commission on the measurement of economic performance and social progress.

Strunk, D.R., Lopez, H., and DeRubeis, R.J. (2006). Depressive symptoms are associated with unrealistic negative predictions of future life events. Behaviour Research and Therapy, 44 (6), $861-882$. DOI

Veenhoven, R. (2014). World database of happiness. Encyclopedia of Quality of Life and Well-Being Research, 7257-7260.

Walker, W. R., Skowronski, J. J. \& Thompson, C. P. (2003). Life is pleasant - and memory helps to keep it that way! Review of General Psychology, 7 (2), 203-210. DOI

Walker, W. R., \& Skowronski, J. J. (2009). The fading affect bias: But what the hell is it for?. Applied Cognitive Psychology: The Official Journal of the Society for Applied Research in Memory and Cognition, 23(8), 1122-1136. DOI

Zanon, C., Bardagi, M. P., Layous, K., \& Hutz, C. S. (2013). Validation of the satisfaction with life scale to Brazilians: Evidences of measurement noninvariance across Brazil and US. Social Indicators Research, 119(1), 443-453. DOI 